\title{
Editorial
}

\section{Metodologia Qualitativa e Pesquisa em Saúde Coletiva}

I Kenneth R. de Camargo Jr., Maria Lúcia Magalhães Bosi |

A esta altura da história, em que nos deparamos com problemáticas cada vez mais complexas impondo igualmente a busca de ferramentas de análise multidimensionais, consoante a complexidade dos fenômenos, seria de se esperar que as intermináveis e estéreis querelas "quali versus quanti" estivessem relegadas a um passado cada vez mais remoto. Contudo, uma breve visita à literatura no campo da saúde nos reassegura ser ainda oportuno insistir na complementaridade como via promissora, ainda não operacionalizada na extensão necessária nas iniciativas levadas a cabo nesse espaço. Lembrando Bourdieu (2000) - ele próprio exemplo da aplicação de múltiplas modalidades técnicas de pesquisa ao longo de sua carreira -, devemos sempre nos acautelar contra os monomaníacos do método.

Conforme enfatizado no corpo do artigos deste tema, uma concepção dinâmica da ciência e da pesquisa tem como contrapartida a aceitação de que métodos devem ser recrutados de acordo com as necessidades do fazer científico, e não o contrário, o que implica considerar a natureza e as especificidades dos objetos, ou seja, reconhecer o escopo de cada metodologia, seu alcance e suas limitações. Nesse sentido, ao nos referirmos à pesquisa qualitativa em saúde, falamos de um conjunto de vertentes teórico-metodológicas que, superando dialeticamente modelos tradicionais, interessa-se em escutar os pontos de vista dos distintos atores sociais, preocupa-se com desfechos "objetiváveis" mas, para além da mensuração, valoriza a compreensão dos complexos processos subjetivos e simbólicos subjacentes aos mesmos.

É nessa complexidade que se inscreve o projeto deste número, construído por grupos de pesquisadores nesse enfoque no Brasil e na região ibero-americana, vinculando-se a uma inciativa singular, pela primeira vez sediada no Brasil: o IV Congresso Ibero-americano de Pesquisa Qualitativa em Saúde. Presidido pela coautora deste editorial e editora convidada do tema desta edição de 
Physis, agregando ao Laboratório de Avaliação e Pesquisa Qualitativa em Saúde (LAPQS-UFC), por ela liderado, um amplo conjunto de instituições da IberoAmérica, contando ainda com várias parcerias e o apoio da ABRASCO, o evento teve lugar na cidade de Fortaleza (CE), no período de 8 a 11 de setembro de 2010. Dentre os trabalhos apresentados no congresso, vários se destacaram pela qualidade e profundidade das reflexôes. Parte deste conjunto é agora publicada como tema da presente edição, conformando um elenco de textos que abordam a questão da pesquisa orientada pelo enfoque qualitativo de um ponto de vista mais reflexivo, buscando oferecer subsídios teórico-metodológicos a modelos no âmbito da pesquisa e da avaliação em saúde (coletiva).

No primeiro artigo do tema desta edição, Peñaranda et cols. fazem uma narrativa reflexiva de como os métodos inicialmente propostos em um projeto de pesquisa na Colômbia foram se modificando ao longo do tempo, sendo antes de tudo um processo de ressignificação do próprio método. A reflexividade exercitada pelos autores acentua o caráter dialético, bem como a natureza sóciohistórica, com que se reveste a operacionalização dos métodos, notadamente aqueles voltados à compreensão de processos humanos. Em prosseguimento, Silva e Alves, partindo de uma reflexão sociológica sobre a produção de conhecimento e a hegemonia da ciência como "verdade única e universalmente válida", (res) situam a questão do conhecimento leigo sobre saúde e doença, e seu rebatimento sobre as práticas cotidianas de saúde. Na sequência, Bosi et cols. realizam uma análise crítica da categoria "inovação", visando a aportar subsídios para pesquisas na área de saúde mental. Mediante a problematização e a demarcação conceitual efetivadas, as autoras reconfiguram o conceito afirmando seu caráter processual, propondo elementos para modelos multidimensionais, visando a favorecer não apenas a investigação mas processos avaliativos em saúde (mental).

Segue-se a reflexão de Iriart e Caprara sobre os desafios da pesquisa antropológica em saúde, em um contexto histórico no qual o horizonte do processo saúde-doença se expande cada vez mais para o microcosmo das moléculas e riscos, e ao mesmo tempo para a arena mundial de um mundo cada vez mais interligado e complexo, devendo tais componentes virem a compor os eixos nucleares de novas abordagens nas investigaçōes nesse domínio disciplinar, apontando para linhas fundadas na transdisciplinaridade.

$\mathrm{Na}$ linha de uma reflexão sobre a complexidade da mediação nos processos compreensivos, Campos, em seu artigo, enfoca a contribuição teórica dos estudos 
de narrativa como ferramenta metodológica, salientando princípios como inclusão e diversidade, problematizando os chamados processos de construção de consenso e a necessária reflexividade por eles exigida. Finalmente, encerrando o tema, Bosi et al. reiteram o aspecto falacioso da pretensa oposição entre métodos qualitativos e quantitativos, apresentando, com base em análise da produção em Nutrição e Saúde Coletiva, o crescimento de estudos que adotam métodos mistos. Contudo, tal como o artigo tenta ressaltar, no que concerne ao consumo alimentar, ainda são incipientes os esforços orientados por abordagens que superam a redução do binômio alimentação-nutrição, à sua dimensão fisiológica, biologizante, representanda pelo conceito de nutrição, tal como definido pela ciência e pelos modelos ainda hegemônicos nas pesquisas nesse campo.

Abrindo a seção de temas livres, Pezzato e L'Abbate apresentam estudo sobre as práticas de saúde bucal na atenção básica, ao mesmo tempo utilizando o próprio estudo como base para uma reflexão para o uso da metodologia adotada (diários de campo) em outros contextos de pesquisa em Saúde Coletiva. Segue o artigo de Lima e Caponi que, a partir da análise crítica do material de divulgação de um projeto que pretende prevenir e diagnosticar precocemente transtornos mentais na infância e adolescência, descrevem um quadro de ampla medicalização com base no referencial psiquiátrico. Cruz busca demonstrar a tese de Boaventura de Souza Santos sobre a segunda ruptura epistemológica no campo da biomedicina, a partir do discurso e do corpo dos pacientes. O corpo é também o tema do trabalho de Mendes, que ressalta sua importância mesmo dentro da esfera das intervenções "psi”. O artigo de Borba emprega as ferramentas da linguística para estudar a construção da identidade entre travestis, no contexto de intervençôes preventivas do HIV/Aids. O denso trabalho de Martin, apresentado no original, em francês (lembramos que Physis aceita contribuições em inglês, francês e espanhol, além do português), descreve a vivência do sofrimento como experiência socialmente compartilhada, com base em estudos numa unidade de cuidados paliativos em Grenoble (França). Menezes faz uma análise do novo código de ética médica, discutindo suas consequências também para os cuidados paliativos. Valadão e Gomes discutem como a homossexualidade feminina é tradada no campo da saúde, com base em revisão bibliográfica e documental. Pignatti et al. descrevem as redes sociais de apoio de idosos em duas localidades no interior do Mato Grosso. Magalhães et al. fazem uma análise da percepção de 
mulheres em vulnerabilidade social sobre suas próprias condições, discutindo os achados a partir das contribuições de Amartya Sen. Lima e Silveira discutem o uso do sistema de patentes como estratégia econômica da indústria farmacêutica, com base no estudo das solicitações de patentes para polimorfos, evidenciando as repercussões negativas de tal estratégia para o acesso a medicamentos. Alberto et al. caracterizam a evolução histórica, qualitativa e quantitativa, da força de trabalho em saúde no Governo Federal, no período de 2000 a 2008. O trabalho de Freitas et al. apresenta os modelos assistenciais adotados por operadoras privadas do setor saúde, mostrando a restrita incorporação da lógica da atenção integral à saúde. Por fim, encerrando a seção, Souza et al. discutem o matriciamento como instrumento de articulação da rede de saúde mental, com base em estudo de unidades de atenção à saúde mental no Nordeste.

Encerrando esta edição, temos a resenha de Alves sobre o livro Viver por um fio: pobreza e politica social, de Anete Ivo.

Um post recente no blog do The Chronicle of Higher Education (http://chronicle. com/blogs/worldwise/refereeing-in-crisis/28943, acessado em $29 \mathrm{dez} 2011$ ), sob o título "Refereeing in crisis?", inicia-se com as seguintes frases: "Uma das coisas que frequentemente choca novos editores de revistas científicas é a dificuldade que eles enfrentam em obter revisores para artigos. Muitas vezes é preciso abordar uma série de revisores para obter o número necessário de pareceres". A razão de destacarmos aqui este problema, de escala mundial, é dupla: por um lado, como forma de explicar (acompanhada de permanente pedido de desculpas) a demora muitas vezes observada na avaliação de artigos. Por outro, para mais uma vez celebrarmos o trabalho anônimo daqueles que, em última análise, garantem a qualidade daquilo que é publicado em ciência. Ao final desta edição, como parte da tradição que estabelecemos, publicamos a lista de todos os nossos pareceristas de 2011, aos quais mais uma vez, e sempre, agradecemos.

A vocês, a todos os autores e leitores de Physis, desejamos um ótimo 2012.

\section{Referência}

BOURDIEU, Pierre. Introdução a uma sociologia reflexiva. In: . O poder simbólico. 3. Ed. Rio de Janeiro: Bertrand Brasil, 2000. 